\title{
George Sand, CEuvres complètes, B. Didier (dir.), 1860, Le Marquis de Villemer
}

\section{Lise Sabourin}

\section{(2) OpenEdition}

10 Journals

\section{Édition électronique}

URL : http://journals.openedition.org/studifrancesi/10005

DOI : 10.4000/studifrancesi. 10005

ISSN : 2421-5856

Éditeur

Rosenberg \& Sellier

\section{Édition imprimée}

Date de publication : 1 août 2017

Pagination : 378-379

ISSN : 0039-2944

\section{Référence électronique}

Lise Sabourin, "George Sand, E Euvres complètes, B. Didier (dir.), 1860, Le Marquis de Villemer », Studi Francesi [En ligne], 182 (LXI | II) | 2017, mis en ligne le 01 août 2017, consulté le 06 janvier 2021. URL http://journals.openedition.org/studifrancesi/10005; DOI : https://doi.org/10.4000/studifrancesi. 10005

Ce document a été généré automatiquement le 6 janvier 2021.

\section{(c) (†) $\ominus$}

Studi Francesi è distribuita con Licenza Creative Commons Attribuzione - Non commerciale - Non opere derivate 4.0 Internazionale. 


\title{
George Sand, Cuvres complètes, B. Didier (dir.), 1860, Le Marquis de Villemer
}

\author{
Lise Sabourin
}

\section{RÉFÉRENCE}

GEORGE SAND, CEuvres complètes, sous la direction de Béatrice Didier, 1860, Le Marquis de Villemer, présentation, notes et établissement du texte par Andrée Mansau, Paris, Honoré Champion, 2016, 341 pp.

1 Comme l'indique son titre primitif Le Puy, Le Marquis de Villemer se déroule en partie en Auvergne, déjà découverte par George Sand lors d'une cure au Mont-Dore avec son époux en 1827, mais visitée plus abondamment, de Nohant au Vigan, en compagnie d'Alexandre Manceau en juin 1859. L'Agenda tenu par celui-ci et le Journal sandien de ce qui donnera naissance au Voyage en Auvergne sont à la base des descriptions qui font tout le charme de ce roman alertement rédigé.

2 Une famille aristocratique aux ressources compromises par les dettes du fils aîné, le débauché Gaétan, duc d'Aléria, s'installe pour la saison estivale dans son château de Séval en Creuse afin de mener un train de vie plus économe, au regret de la mère, une douairière figée dans ses idées d'Ancien Régime, mais intelligente et charitable. En vérité, ce séjour sied mieux à son fils du second lit, Urbain, marquis de Villemer, qui trouve dans ses recherches historiques, dignes de Michelet, de quoi oublier la naissance d'un enfant illégitime qu'il a mis en nourrice, après la mort de sa mère adultère, au village de Lantriac, chez d'austères paysans.

3 L'amour s'introduit dans cette famille aristocratique du faubourg Saint-Germain rêvant de reconstituer sa fortune par un brillant mariage à cause d'une pauvre orpheline de la petite noblesse, Caroline de Saint-Geneix, qui a elle-même fui un mariage de convenance peu tentant pour se faire demoiselle de compagnie de la vieille marquise et 
permettre ainsi à sa sœur veuve, Camille Heudebert, d'élever ses quatre enfants. Le roman épistolaire, situé de 1845 à début 1848, naît de la relation qu'elle lui fait du quotidien de sa nouvelle tâche: lectures et conversations avec l'ancienne aristocrate, entreprise de séduction du «Lovelace émérite» qu'est le duc d'Aléria, fascination pour le travail et la personnalité sérieuse du marquis. Une amie de couvent, Léonie d'Arglade, selon un poncif que n'évite pas ce roman, se charge de la calomnie traîtresse qui suscite la fuite éperdue de Caroline pour trouver refuge chez sa nourrice, Justine Peyraque, épouse d'un parpaillot cévenol. C'est là, bien sûr, que le hasard lui fera retrouver Didier, le fils d'Urbain, puis tenter une traversée du mont Mézenc sous la neige afin d'échapper à la poursuite du marquis avant qu'ils ne s'avouent leurs sentiments réciproques.

4 En fait, l'aspect mélodramatique du sentimentalisme un peu convenu de l'intrigue masque un roman réaliste et romantique à la fois. George Sand y transcrit, quoique sans aspects autobiographiques, en scènes personnelles sa dénonciation du manque d'autonomie féminine et sa quête difficile du bonheur. Mais elle situe ses idées sur fond d'observation du Velay, avec ses paysans chanteurs, ses rouliers, ses bouviers, qui, tout en conservant leurs rudes mœurs, vivent déjà la modernité, que marque par exemple l'exploitation des dentellières par les commerçants, y compris les religieuses du Puy. Ce pays des «anciens sauvages» aux racines celtiques fournit, outre la beauté de ses paysages et de ses ruines, l'occasion de décrire l'habitat rural et la géologie des volcans qu'aime la romancière. Sand inverse subtilement la méthode balzacienne aussi bien que stendhalienne pour retracer une aristocratie dépassée plutôt que déchue et une société villageoise plus que paysanne, où triomphe une vertu à la Florian, avec quelques touches de Richardson et Scott qui mènent au double mariage final. Le dangereux viveur Gaétan est régénéré par l'amour d'une délicieuse et riche Diane de Xaintrailles; Urbain s'unit à Caroline, qui devient ainsi la nouvelle marquise accueillant en son château provincial les enfants de sa sœur comme le bâtard de son mari.

5 Le manuscrit, rédigé du 23 mars au 3 juin 1860, suscita d'ailleurs quelques discussions orageuses avec Buloz qui proposa des interventions, dont Sand accepta certaines (raccourcissements, éviction de digressions, éclaircissements de sens), mais refusa d'autres pour maintenir sa vision d'une société future sans classe et sans souci de filiation. La parution dans la «Revue des deux mondes», du 15 juillet au 15 septembre 1860, puis en volume chez Michel Lévy en 1861, avec quelques remaniements structurels de chapitres, suscita une réception assez élogieuse de ce roman qui se hisse au niveau de La Petite Fadette ou de La Mare au diable par l'étude de la naissance des passions, la qualité de ses évocations de nature et l'alacrité de son style. Stevenson suivit d'ailleurs son itinéraire pour son Voyage avec un âne dans les Cévennes en 1879.

6 Andrée Mansau en donne une édition honorable (quelques coquilles, comme «fraternel» au lieu de «paternel», p. 168), quoique peu annotée (aucune allusion aux autres œuvres sandiennes), avec présentation (pp. 7-30) et annexes (pp. 313-333) qui fournissent les variantes du manuscrit (assez maladroitement présentées), les sources de l'Agenda et du Journal, les lettres échangées avec Buloz, des extraits des critiques de Prévost-Paradol, Seillière, Malot, Cuvillier-Fleury et Zola, la liste des traductions, une courte bibliographie et les habituels index des noms de pays et lieux, de personnages historiques et références mythologiques. 